This item was submitted to Loughborough's Research Repository by the author.

Items in Figshare are protected by copyright, with all rights reserved, unless otherwise indicated.

\title{
Increasing heat storage by wearing extra clothing during upper body exercise up-regulates heat shock protein 70 but does not modify the cytokine response
}

\section{PLEASE CITE THE PUBLISHED VERSION}

http://dx.doi.org/10.1080/02640414.2016.1235795

\section{PUBLISHER}

(c) Taylor \& Francis

\section{VERSION}

AM (Accepted Manuscript)

\section{PUBLISHER STATEMENT}

This work is made available according to the conditions of the Creative Commons Attribution-NonCommercialNoDerivatives 4.0 International (CC BY-NC-ND 4.0) licence. Full details of this licence are available at: https://creativecommons.org/licenses/by-nc-nd/4.0/

\section{LICENCE}

CC BY-NC-ND 4.0

\section{REPOSITORY RECORD}

Leicht, Christof A., A. Papanagopolous, S. Haghighat, and Steve H. Faulkner. 2019. "Increasing Heat Storage by Wearing Extra Clothing During Upper Body Exercise Up-regulates Heat Shock Protein 70 but Does Not Modify the Cytokine Response". figshare. https://hdl.handle.net/2134/22467. 


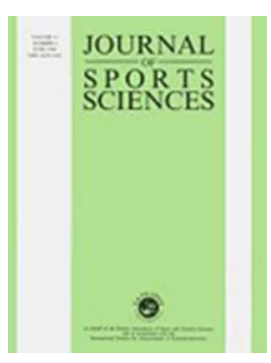

Increasing heat storage by wearing extra clothing during upper body exercise up-regulates heat shock protein 70 but does not modify the cytokine response

\begin{tabular}{|r|l|}
\hline Journal: & Journal of Sports Sciences \\
\hline Manuscript ID & RJSP-2016-0526.R2 \\
\hline Manuscript Type: & Original Manuscript \\
\hline Keywords: & heat stress, temperature, arm cranking, interleukin-6, Inflammation \\
\hline \multicolumn{2}{|l}{} \\
\hline
\end{tabular}

SCHOLARONE $^{\text {Ix }}$

Manuscripts 
Increasing heat storage by wearing extra clothing during upper body exercise upregulates heat shock protein 70 but does not modify the cytokine response

Running title:

Arm exercise, heat stress, cytokines and HSP70

Key words: heat stress; temperature; arm cranking; inflammation; interleukin-6 


\begin{abstract}
Plasma heat shock protein 70 (HSP70) concentrations rise during heat stress, which can independently induce cytokine production. Upper body exercise normally results in modest body temperature elevations. The aim of this study was to investigate the impacts of additional clothing on the body temperature, cytokine and HSP70 responses during this exercise modality. Thirteen males-individuals_performed 45-min constant load arm cranking at $63 \%$ maximum aerobic power $\left(62 \pm 7 \% \dot{\mathrm{VO}}_{2 \text { peak }}\right)$ in either a non-permeable whole body suit (intervention, INT) or shorts and T-shirt (control, CON). Exercise resulted in a significant increase of IL-6 and IL-1ra plasma concentrations $(P<0.001)$, with no difference between conditions $(P>0.19)$. The increase in HSP70 from pre to post was only significant for INT $\left(0.12 \pm 0.11 \mathrm{ng} \cdot \mathrm{mL}^{-1}, P<0.01\right.$; vs $\left.0.04 \pm 0.18 \mathrm{ng} \cdot \mathrm{mL}^{-1}, P=0.77\right)$. Immediately following exercise, $\mathrm{T}_{\text {core }}$ was elevated by $0.46 \pm 0.29$ (INT) and $0.37 \pm 0.23^{\circ} \mathrm{C}$ $(\mathrm{CON})$, respectively $(P<0.01)$, with no difference between conditions $(P=0.16)$. The rise in mean $\mathrm{T}_{\text {skin }}\left(2.88 \pm 0.50\right.$ and $0.30 \pm 0.89^{\circ} \mathrm{C}$, respectively) and maximum heat storage $\left(3.24 \pm 1.08\right.$ and $1.20 \pm 1.04 \mathrm{~J} \cdot \mathrm{g}^{-1}$, respectively) were higher during INT $(P<0.01)$. Despite large differences in heat storage between conditions, the HSP70 elevations during INT, even though significant, were very modest. Possibly, the $\mathrm{T}_{\text {core }}$ elevations were too low to induce a more pronounced HSP70 response to ultimately affect cytokine production.
\end{abstract}




\section{Introduction}

Several chronic diseases such as cardiovascular disease, type 2 diabetes and some cancers are associated with chronic low grade inflammation, which manifests as elevated resting concentration of a range of pro-inflammatory markers. Regular exercise has the potential to reduce the resting concentration of these markers, which may lower the disease risk and therefore represent a non-pharmacological disease prevention approach. It has been suggested that this may be partly a result of the repeated creation of an acute antiinflammatory environment in the recovery period after each bout of exercise (Gleeson et al., 2011). This anti-inflammatory environment may be partly created by acute secretion of pro-inflammatory cytokines such as interleukin-6 (IL-6) that can independently upregulate anti-inflammatory markers such as IL-10 or IL-1ra (Steensberg, Fischer, Keller, Moller \& Pedersen, 2003).

An acute cytokine response, similar to the one found following exercise, has also been reported following temperature increases in non-exercising conditions: this response has been found both in isolated muscle ex vivo (Welc, Judge \& Clanton, 2013), but also when passively immersing humans in hot water (Leicht et al., 2015; Laing et al., 2008). Increased circulating cytokines in hot conditions may be a result of an increased secretion by immune cells that can be found in higher numbers in the circulation (Starkie, Hargreaves, Rolland \& Febbraio, 2005) and may change their secretory behaviour. Heat can also induce the formation of heat shock factors within cells, which contribute to the transcription of IL-6 protein (Welc \& Clanton, 2013). Finally, a range of conditions associated with stress, including exercise or heat exposure, are linked to elevated plasma concentrations of the $70 \mathrm{kDa}$ family of heat shock proteins (HSP70/HSP72) (Whitham \& 
Fortes, 2008). With respect to the inflammatory response, it is important to note that HSP70 can independently induce the production of pro-inflammatory cytokines (Tsan \& Gao, 2004; Wallin et al., 2002).

Populations restricted to upper body exercise include wheelchair users or those with lower limb injuries. Such populations are at a higher risk to develop chronic disease associated with chronic low grade inflammation (Myers, Lee \& Kiratli, 2007). This may be a result of a smaller physical capacity, a smaller active muscle mass that may affect cytokine production and reduced access to and therefore participation in sports. Furthermore, temperature effects on the inflammatory response are likely to be markedly reduced as the core temperature $\left(\mathrm{T}_{\text {core }}\right)$ increase during upper body exercise is substantially lower when compared with lower body exercise of the same relative intensity (Gass \& Gass, 1998). Whilst upper body exercise is a modality that can induce an acute cytokine response at room temperature (Leicht, Paulson, Goosey-Tolfrey \& Bishop, 2016; Paulson, Goosey-Tolfrey, Leicht \& Bishop, 2015), enhancing this response in these at risk populations may help to optimise individual exercise sessions with regards to the inflammatory profile. A promising method to enhance the cytokine response may be the addition of heat stress to exercise, which has been shown to be an effective method during lower body exercise (Laing et al., 2008; Starkie et al., 2005; Brenner et al., 1999). Whether similar effects can be observed in the upper body exercise modality with a reduced heat production remains to be elucidated.

The aim of this study was to investigate the impacts of heat stress on the temperature, cytokine and HSP70 responses during upper body exercise. We hypothesizssed that 
exercise alone will result in acute elevations of cytokines and HSP70, but that this response would be magnified with additional heat stress.

\section{Materials and methods}

\subsection{Participants}

Thirteen recreationally trained male-individuals (age: $24 \pm 2$ years; body mass: $83.7 \pm 9.7$ $\mathrm{kg}$; height: $181 \pm 8 \mathrm{~cm}$ ) volunteered to participate in this study, which was approved by the University's Ethics committee, conforming to the requirements stipulated in the Declaration of Helsinki. They were moderately trained (sporting activity: $4.0 \pm 1.6$ $\mathrm{h} \cdot$ week $^{-1}$ ), with an arm exercise $\dot{\mathrm{V}} \mathrm{O}_{2 \text { peak }}$ of $2.7 \pm 0.6 \mathrm{~L} \cdot \mathrm{min}^{-1}$ and $32.9 \pm 8.5 \mathrm{~mL} \cdot \mathrm{kg}^{-1} \cdot \mathrm{min}^{-1}$, respectively. Their peak heart rate during this modality was $181 \pm 7 \mathrm{~b} \cdot \mathrm{min}^{-1}$.

\subsection{Experimental design}

Participants visited the laboratory on three occasions for one preliminary and two main trials. In the preliminary trial, body mass and height were determined (seca 285, seca GmBH, Hamburg, Germany) followed by determination of peak oxygen consumption ( $\dot{\mathrm{V}}_{2 \text { peak }}$ ) during arm exercise using an arm crank ergometer (Angio, Lode, Groningen, Holland). Participants performed a graded exercise test to exhaustion, with an initial power output of $35 \mathrm{~W}$; every three minutes power output was increased by $15 \mathrm{~W}$ until exhaustion. Maximum power output $\left(\mathrm{P}_{\max }\right)$ was defined as the work rate achieved during the final minute of the test. If the final stage was not fully completed, $\mathrm{P}_{\max }$ was set pro rata according to the fraction of time of the completed 3-min stage. Exercise was performed in a sitting position, the centre of the crank at shoulder level with arms slightly flexed at maximum reach. Settings were noted and used for all main trials. Oxygen 
uptake was determined in each stage using the Douglas bag technique with a Servomex 1440 (Servomex Ltd, Crowborough, UK), the highest value was defined as $\dot{\mathrm{V}} \mathrm{O}_{2 \text { peak }}$.

Main trials consisted of 45 min of steady state arm cranking exercise at $65 \% \mathrm{P}_{\max }$ for the first $30 \mathrm{~min}$ and at $60 \% \mathrm{P}_{\max }$ for the final $15 \mathrm{~min}$. The control (CON) trial was performed in normal sportswear (shorts and T-shirt) with a fan directed at the participant throughout the exercise. In the intervention (INT) trial an additional full body suit made of nonpermeable Bri-Nylon fabric including hood was worn during the exercise, leaving only the feet, hands and face exposed; no fan was used in this condition, and in the recovery the same sportswear as for CON was worn.

Main trials were performed in a randomised order after a $24 \mathrm{~h}$ food standardisation period without caffeine and with no exercise allowed $24 \mathrm{~h}$ before the experiments. To account for diurnal variations of $\mathrm{T}_{\text {core }}$, exercise tests were performed at midday (start: 11:0013:40) for all participants and at the same time of day for each individual participant.

Upon arrival to the laboratory, participants were fitted with a rectal thermometer (YSI 400 series, OH, USA) and skin thermistors (DS1922L-F5 thermochrons, Homechip Ltd, Milton Keynes, UK) at 10 locations using strips of water-permeable surgical tape (3M Transpore, Loughborough, UK) according to the site-modified Colin and Houdas formula (Choi, Miki, Sagawa \& Shiraki, 1997). Trials were performed at room temperature (INT $20.6 \pm 0.5^{\circ} \mathrm{C}, \mathrm{CON} 20.7 \pm 0.5^{\circ} \mathrm{C}$ ) and a relative humidity of $34.8 \pm 6.1 \%$ (INT) and 34.8 $\pm 5.1(\mathrm{CON})$, respectively. Resting temperature data were obtained following $5 \mathrm{~min}$ of seated rest wearing shorts and a T-shirt. A five-minute warm-up in shorts and T-shirt was then performed at $50 \%$ of the start power output before each condition. During exercise, oxygen uptake was determined in $7.5 \mathrm{~min}$ intervals, and heart rate continuously 
monitored (RS400, POLAR, Kempele, Finland) monitor. Participants indicated their rating of perceived exertion (RPE) on a scale ranging from 6 to 20 (Borg, 1982) and their exercise comfort from -5 to +5 (Hardy \& Rejeski, 1989). Participants indicated their thermal perception from "very cold" (0) to "very hot" (20) (Lee, Stone, Wakabayashi \& Tochihara, 2010) and their thermal comfort from "maximally uncomfortable" (0) to "maximally comfortable" (20) (Nakamura et al., 2008) on a visual analogue scale every 7.5 min. Water during exercise was given ad libitum, food and other drinks than water were not allowed during the main trials.

Venous blood samples were collected into $\mathrm{K}_{3}$ EDTA containers from a superficial arm vein with participants in a supine position before, immediately after, and at $2 \mathrm{~h}$ after exercise. Haemoglobin concentration was determined in duplicate using the cyanmethaemoglobin method using a spectrophotometer (CECIL CE1011, Cecil Instruments Ltd., Cambridge, UK). Haematocrit was determined using a microlitre centrifuge (Mikro20, Andreas Hettich GmbH, Tuttlingen, Germany). Plasma volume changes were estimated from haemoglobin and haematocrit (Dill \& Costill, 1974) and plasma concentration of all analytes corrected for changes in plasma volume.

Following centrifugation $\left(5 \mathrm{~min}\right.$ at $3000 \mathrm{rpm}$ and $4^{\circ} \mathrm{C}$ ) plasma was stored at $-20^{\circ} \mathrm{C}$ until analysis. The following analytes were determined in duplicate by enzyme-linked immunosorbent assay (ELISA) using a microplate reader (Varioskan Flash, ThermoScientific, Waltham, USA): IL-6 (high sensitivity), IL-1 ra (R\&D systems, Minneapolis, US), and HSP70 (Amp'd HSP70 High Sensitivity, Enzo Life Sciences, Farmingdale, US). The within assay co-efficients of variation for the analyses based on evaluation of the standards were: IL-6 9.6 $\pm 7.2 \%$, IL-1ra $6.9 \pm 4.9 \%$, HSP70 $5.2 \pm 3.3 \%$. 


\subsection{Data processing and statistical analyses}

Skin temperature $\left(\mathrm{T}_{\text {skin }}\right)$ was recorded every $5 \mathrm{~s}$ throughout exercise and a $30 \mathrm{~min}$ recovery period and averaged every $7.5 \mathrm{~min}$ for each thermistor location independently. Mean $\mathrm{T}_{\text {sk }}$ was calculated according to the modified Colin and Houdas formula (Choi et al., 1997). Heat storage was determined as:

$$
\text { Heat storage }\left(\mathrm{J} \cdot \mathrm{g}^{-1}\right)=\left(0.8 \cdot \Delta \mathrm{T}_{\text {core }}+0.2 \cdot \Delta \mathrm{T}_{\text {skin }}\right) \cdot \mathrm{c}_{\mathrm{b}}
$$

where $\mathrm{c}_{\mathrm{b}}$ is the specific heat of body tissue $\left(3.49 \mathrm{~J} \cdot \mathrm{g}^{-1} \cdot{ }^{\circ} \mathrm{C}^{-1}\right)$ and $\Delta \mathrm{T}_{\text {core }}$ and $\Delta \mathrm{T}_{\text {skin }}$ indicate the changes in $\mathrm{T}_{\text {core }}$ and $\mathrm{T}_{\mathrm{sk}}$ from rest to the respective time point (Havenith, Luttikholt \& Vrijkotte, 1995). Sweat production was calculated subtracting the body mass measured after recovery from body mass before exercise, accounting for fluid intake during this period.

The SPSS 22.0 statistical package (SPSS Inc., Chicago IL, USA) was used for all statistical analyses. Means and standard deviations were computed for all variables, and normality was checked with the Shapiro Wilk test. Non-normal data were converted using logarithmic transformations to achieve normality. A repeated measures two-way (exercise modality, time) analysis of variance (ANOVA) was conducted on normally distributed blood derived and temperature variables. Huynh-Feldt corrections were applied when sphericity was violated and Sidak adjustments applied for any post-hoc comparisons. The plasma marker changes from pre to post were additionally analysed using one sample t-tests against a test value of Zero for both exercise conditions separately, and effect sizes (ES) were calculated for these analyses (Cohen's $d=\mathrm{t}$ test statistic $\div \sqrt{ } \mathrm{N}$ ). Temperature data were further analysed between conditions using paired sample t-tests. Physiological exercise descriptors were analysed using a one-way 
(exercise modality) repeated measures ANOVA or the non-parametric equivalents for non-normal and RPE data; subjective responses were analysed for the last $7.5 \mathrm{~min}$ of exercise. Ninety-five percent confidence intervals (CI) were calculated for differences between conditions and/or time points; Bonferroni corrections were applied for any multiple comparisons. Statistical significance was accepted at $\mathrm{P}<0.05$. Post hoc power calculations performed with GPower 3.1 indicated that the statistical power for the pre to post HSP70 response was 0.97 for INT.

\section{Results}

Exercise resulted in a significant increase of IL-6 and IL-1ra plasma concentrations $(P<0.001)$, which did not differ between conditions $(P>0.19$, Figure 1$)$. The increase in HSP70 from pre to post was only significantly different from Zero for INT (INT: $P=$ $0.004, \mathrm{CI}=0.05-0.18 \mathrm{ng} \cdot \mathrm{mL}^{-1}, \mathrm{ES}=1.06 ; \mathrm{CON}: P=0.77, \mathrm{CI}=-0.06-0.15 \mathrm{ng} \cdot \mathrm{mL}^{-1}$, $\mathrm{ES}=0.25)$, whereas it was significantly different from Zero for both INT and CON for IL-6 (INT: $P<0.001, \mathrm{CI}=0.91-1.80 \mathrm{pg} \cdot \mathrm{mL}^{-1}, \mathrm{ES}=1.84$; $\mathrm{CON}: P=0.002, \mathrm{CI}=0.62-$ $1.85 \mathrm{pg} \cdot \mathrm{mL}^{-1}, \mathrm{ES}=1.22 ;$ Figure 2).

****Figures 1-3 near here $* * * *$

Oxygen uptake $\left(62 \pm 6\right.$ vs $\left.62 \pm 7 \% \dot{\mathrm{VO}}_{2 \text { peak }}, P=0.51, \mathrm{CI}=-4-3 \% \dot{\mathrm{VO}}{ }_{2 \text { peak }}\right)$ and respiratory exchange rate $(1.06 \pm 0.04$ vs $1.05 \pm 0.05, P=0.50, \mathrm{CI}=-0.02-0.04)$ did not differ between conditions. Mean exercise heart rate was significantly elevated in INT vs CON $\left(143 \pm 13\right.$ vs $134 \pm 14$ beats $\cdot \min ^{-1}, P=0.004, \mathrm{CI}=4-15$ beats $\left.\cdot \mathrm{min}^{-1}\right)$. Exercise significantly elevated $\mathrm{T}_{\text {core }}$ in both conditions $(P<0.001)$, however, a significant time $\mathrm{x}$ condition interaction was found $(P=0.006)$, and the $\mathrm{T}_{\text {core }}$ change was elevated 
throughout the trial $\left(P=0.001, \mathrm{CI}=0.07-0.23{ }^{\circ} \mathrm{C} \cdot \mathrm{h}^{-1}\right)($ Figure 3$)$. This resulted in a significant difference in $\mathrm{T}_{\text {core }}$ between conditions which became apparent in the recovery period $\left(P=0.03, \mathrm{CI}=0.10-0.36{ }^{\circ} \mathrm{C}\right)$. The mean $\mathrm{T}_{\text {skin }}\left(\mathrm{CI}=1.36-1.98{ }^{\circ} \mathrm{C}\right)$ and heat storage $\left(\mathrm{CI}=0.74-1.62 \mathrm{~J} \cdot \mathrm{g}^{-1}\right)$ were significantly elevated during INT $(P<0.05$, Figure 3).

Sweat production was significantly elevated in INT $(0.75 \pm 0.28$ vs $0.49 \pm 0.19 \mathrm{~L}, P<$ $0.001, \mathrm{CI}=0.15-0.36 \mathrm{~L}$ ) with no differences in water consumed between conditions (INT: $0.67 \pm 0.35$ vs CON: $0.47 \pm 0.34 \mathrm{~L}, P=0.09, \mathrm{CI}=-0.44-0.04 \mathrm{~L}$ ). All perceptual measures for effort and temperature were different between conditions (Table I).

$* * * *$ Table I near here****

\section{Discussion}

The main finding of this study was that whilst arm cranking exercise did induce acute elevations of IL-6 and IL-1ra concentrations, the cytokine response was not magnified by increasing heat stress. Exercising in a full body suit, however, induced a small but significant increase of HSP70 plasma concentration, which was absent when exercising in normal sportswear. The whole body suit only mildly affected the $\mathrm{T}_{\text {core }}$ response, but induced $\mathrm{a} \sim 3$-fold rise in heat storage.

To our knowledge, this is the first study investigating the impact of heat stress on the cytokine and HSP70 response in upper body exercise. Given the importance of temperature elevations in this response (Welc et al., 2012), this exercise modality may particularly benefit from interventions increasing heat stress, as in contrast to lower body 
exercise, upper body exercise generates less metabolic heat and as such the increases in $\mathrm{T}_{\text {core }}$ for the same relative exercise intensity are lower for this modality (Gass \& Gass, 1998). Lower body exercise comparable in relative intensity and duration as the present study induces two to three times the increase in $\mathrm{T}_{\text {core }}$ when performed in cool or thermoneutral conditions (Gibson et al., 2014; Whitham, Laing, Jackson, Maassen \& Walsh, 2007; Niess et al., 2003). Previous studies support the hypothesis that exercise which results in a higher $T_{\text {core }}$ magnifies the IL- 6 response when compared to a control condition. Some studies show trends (Niess et al., 2003), whilst for others the difference is significant (Laing et al., 2008; Starkie et al., 2005; Brenner et al., 1999). However, it is important to note that the difference in $\mathrm{T}_{\text {core }}$ between conditions in these studies is more pronounced when compared with the present study, and in the range of $1-2{ }^{\circ} \mathrm{C}$ following exercise. Even though a significant difference between conditions in the $\mathrm{T}_{\text {core }}$ change was found in the present study, the resulting difference in $\mathrm{T}_{\text {core }}$ was small $\left(\sim 0.2{ }^{\circ} \mathrm{C}\right)$ and not apparent until $30 \mathrm{~min}$ post exercise. It is therefore pessible-likely that the minimal impact of additional clothing on $\mathrm{T}_{\text {core }}$ was insufficient to substantially modify the IL-6 and IL-1ra response. Hence, it cannot be ruled out that more pronounced increases in $\mathrm{T}_{\text {core }}$ would have led to a greater increase in cytokines in the upper body exercise modality as demonstrated previously for lower body exercise (Laing et al., 2008; Starkie et al., 2005; Brenner et al., 1999). Evidence from non-exercising studies, either based on incubation experiments (Welc et al., 2012) or passive hyperthermia in animals (Welc et al., 2012) or humans (Leicht et al., 2015), supports the concept of the independent up-regulation of IL6 protein by temperature only. However, the approach of the present study to use a whole body suit to increase heat stress must be reconsidered in the context of increasing $\mathrm{T}_{\text {core }}$. Even though it represents a practical method that could be applied more easily on a population level than water immersion based procedures or exercise at high temperatures 
and/or humidity, it does not appear to be effective in substantially modifying the $\mathrm{T}_{\text {core }}$ response to exercise. Despite being less practical, the combined effect of hot water immersion and exercise would certainly result in higher $\mathrm{T}_{\text {core }}$ elevations, as shown for passive hot water immersion (Leicht et al., 2015; Whitham et al., 2007). Alternatively, as our results imply a linear increase of $\mathrm{T}_{\text {core }}$ up to $45 \mathrm{~min}$ of exercise (notably during INT), a greater increase in $\mathrm{T}_{\text {core }}$ from resting conditions is likely to be achieved by extending the exercise duration. Altering exercise protocols in these ways may help to affect the cytokine response during upper body exercise.

Whilst the cytokine response was not different between conditions, differences in the plasma HSP70 response were found in the present study. Apart from its intracellular chaperoning function, HSP70 in the extracellular environment has a cytokine function, and can therefore affect the release of other cytokines such as IL-6 (Tsan \& Gao, 2004). HSP70 is released from a multitude of human cells such as the hepatosplanchnic tissue, immune and epithelial cells, or the brain (Whitham \& Fortes, 2008; Yamada, Amorim, Moseley \& Schneider, 2008), all these cells hence contribute to the level of circulating HSP70 concentrations. Many of these cells are located centrally; it could hence be hypothesizsed that central elevations of temperature have a more pronounced effect than surface temperature elevations. However, we propose that the difference in HSP70 elevations is associated with the difference in heat storage between conditions. This measure takes into consideration changes in both core and surface temperature to estimate the average temperature elevation across the body; it is therefore possible that the pronounced difference in heat storage between conditions had an effect on the increase in HSP70 immediately after exercise. The present data hence suggest that heat storage may be the more appropriate parameter to predict elevations in HSP70 than $\mathrm{T}_{\text {core }}$ 
elevations in isolation, as $\mathrm{T}_{\text {core }}$ was not different between conditions between the pre and post measurement period where the higher rise in HSP70 was found for INT. The authors are aware that heat storage as calculated in the present study is a very rough approximation of the average heat gain within the body, as it has been shown that the two-compartment model using only $\mathrm{T}_{\text {core }}$ and $\mathrm{T}_{\text {skin }}$ underestimates heat storage when compared with three-compartment models, which take muscle temperature into account (Jay et al., 2007). It is therefore likely that the actual heat storage in the present study was higher than the calculated values, due to higher than average temperatures in the muscle compartment - an important factor to consider should the present data be directly compared to studies using the three compartment model.

Alpha-adrenergic receptor stimulation has been shown to increase intracellular HSP70 expression in a variety of tissues such as brown adipose tissue, myocardium, and immune cells (Whitham \& Fortes, 2008). Animal studies further indicate that alpha adrenergic receptor mediated signalling pathways are involved in the increase of extracellular HSP70 (Johnson et al., 2005). Even though not directly measured in the current study, heat stress is associated with increases in sympathetic activity (Starkie et al., 2005; Rhind et al., 1999), which has been previously suggested to be a mechanism modulating immune responses (Rhind et al., 1999). The differences in heart rate or ratings of perceived exertion between conditions indicate that INT was the more stressful condition that could be associated with increased sympathetic activity, which would further explain the difference in HSP70 elevations found between conditions.

The present HSP70 data are in line with studies that document a magnified HSP70 response when performing exercise during additional heat stress (Ogura et al., 2008; 
Whitham et al., 2007). Even though factors other than temperature, such as psychological stress, trauma, or infection, can increase HSP70 plasma concentrations (Asea, 2006), temperature clamping or increased heat stress during exercise demonstrates the crucial role of cell temperature on HSP70 plasma concentration (Ogura et al., 2008; Whitham, et al., 2007). This is also demonstrated by the proportional increase in extracellular HSP70 concentration with increasing temperature in peripheral blood mononuclear cells (Lancaster \& Febbraio, 2005). The importance of temperature on the HSP response is further reflected by the positive relationships that have previously been found between exercise duration and plasma HSP70 concentration and exercise intensity and plasma HSP70 concentration (Fehrenbach, Niess, Voelker, Northoff \& Mooren, 2005).

Whilst some interventions have failed to document an increase in plasma HSP70 concentrations following exercise combined with moderate heat stress (Gibson et al., 2014), a number of studies summarised by Yamada, Amorim, Moseley \& Schneider (2008) have shown HSP70 elevations following moderate to exhaustive exercise. It is important to note that the sensitivity of the procedures to quantify HSP70 may affect any conclusions. In the current study, the HSP70 resting concentration was in the range of 0.7 $\mathrm{ng} \cdot \mathrm{mL}^{-1}$, and the HSP70 concentration change from pre to post during INT in the range of $0.1 \mathrm{ng} \cdot \mathrm{mL}^{-1}$ (a 16\% increase from resting). Biochemical methods to detect protein concentrations with a sensitivity of down to $1 \mathrm{ng} \cdot \mathrm{mL}^{-1}$ would therefore not be able to detect the true resting concentration or indeed any small increase from resting. This may partly explain why Gibson et al. (2014) only detected HSP70 changes when $\mathrm{T}_{\text {core }}$ changes were in excess of $2{ }^{\circ} \mathrm{C}$. However, it is important to note that the extent of the HSP change of the current study (16\%) is a very modest increase when compared to existing studies investigating lower body exercise where increases of $200-1600 \%$ have been documented 
(Yamada et al., 2008). In analogy to our interpretation of the cytokine response, it is possible that more pronounced $\mathrm{T}_{\text {core }}$ elevations could have led to more pronounced increases in HSP70. This, in turn, may then directly affect the cytokine response as a result of the mechanistic role of extracellular HSP in the process of cytokine secretion (Tsan \& Gao, 2004; Wallin et al., 2002).

\section{Conclusion}

Despite large differences in heat storage between conditions, the elevations in HSP70 during INT, even though significant, were very modest. The arm cranking protocol resulted in a pronounced elevation of IL-6 and IL-1ra, but this response was not affected by increasing heat stress. Possibly, the $\mathrm{T}_{\text {core }}$ elevations were too low to induce a more pronounced HSP70 response that could ultimately affect cytokine production. If increasing the cytokine response through additional heat stress during upper body exercise is the aim, alternative methods to elevate $\mathrm{T}_{\text {core }}$ should be explored, as further increasing heat stress using additional clothing may be perceived as too uncomfortable to be of practical value.

\section{Conflict of interest}

The authors declare no conflict of interest. 


\section{Figure captions}

Figure 1 - Interleukin-6 (IL-6), IL-1ra and HSP70 response to arm exercise with (INT) and without $(\mathrm{CON})$ additional clothing. Significantly different from *pre or **post $(\mathrm{P}<0.01)$.

Figure 2 - Increases in IL-6 and HSP70 from pre to post. *Significantly different from Zero $(\mathrm{P}<0.05)$.

Figure 3 - Core temperature, core temperature change, mean skin temperature, and heat storage. *Significantly different between conditions $(\mathrm{P}<0.05)$.

\section{Table captions}

Table I - Perceptions of effort, feeling and temperature. 


\section{References}

1. Asea, A. (2006). Initiation of the Immune Response by Extracellular Hsp72: Chaperokine Activity of Hsp72. Current immunology reviews, 2, 209-215.

2. Borg, G.A. (1982). Psychophysical bases of perceived exertion. Medicine and science in sports and exercise, 14, 377-381.

3. Brenner, I.K., Castellani, J.W., Gabaree, C., Young, A.J., Zamecnik, J., Shephard, R.J. \& Shek, P.N. (1999). Immune changes in humans during cold exposure: effects of prior heating and exercise. Journal of applied physiology (Bethesda, Md.: 1985), 87, 699-710.

4. Choi, J.K., Miki, K., Sagawa, S. \& Shiraki, K. (1997). Evaluation of mean skin temperature formulas by infrared thermography. International journal of biometeorology, 41, 68-75.

5. Dill, D.B. \& Costill, D.L. (1974). Calculation of percentage changes in volumes of blood, plasma, and red cells in dehydration. Journal of applied physiology, 37, 247248.

6. Fehrenbach, E., Niess, A.M., Voelker, K., Northoff, H. \& Mooren, F.C. (2005). Exercise intensity and duration affect blood soluble HSP72. International journal of sports medicine, 26, 552-557.

7. Gass, E.M. \& Gass, G.C. (1998). Rectal and esophageal temperatures during upperand lower-body exercise. European journal of applied physiology and occupational physiology, 78, 38-42.

8. Gibson, O.R., Dennis, A., Parfitt, T., Taylor, L., Watt, P.W. \& Maxwell, N.S. (2014). Extracellular Hsp72 concentration relates to a minimum endogenous criteria during acute exercise-heat exposure. Cell stress \& chaperones, 19, 389-400.

9. Gleeson, M., Bishop, N.C., Stensel, D.J., Lindley, M.R., Mastana, S.S. \& Nimmo, M.A. (2011). The anti-inflammatory effects of exercise: mechanisms and implications for the prevention and treatment of disease. Nature reviews.Immunology, 11, 607-615.

10. Hardy, C.J. \& Rejeski, W. (1989). Not what, but how one feels - the measurement of affect during exercise. Journal of sport \& exercise psychology; J.Sport Exerc.Psychol., 11, 304-317.

11. Havenith, G., Luttikholt, V.G. \& Vrijkotte, T.G. (1995). The relative influence of body characteristics on humid heat stress response. European journal of applied physiology and occupational physiology, 70, 270-279.

12. Jay, O., Gariepy, L.M., Reardon, F.D., Webb, P., Ducharme, M.B., Ramsay, T. \& Kenny, G.P. (2007). A three-compartment thermometry model for the improved 
estimation of changes in body heat content. American journal of physiology.Regulatory, integrative and comparative physiology, 292, R167-75.

13. Johnson, J.D., Campisi, J., Sharkey, C.M., Kennedy, S.L., Nickerson, M. \& Fleshner, M. (2005). Adrenergic receptors mediate stress-induced elevations in extracellular Hsp72. Journal of applied physiology (Bethesda, Md.: 1985), 99, 1789-1795.

14. Laing, S.J., Jackson, A.R., Walters, R., Lloyd-Jones, E., Whitham, M., Maassen, N. \& Walsh, N.P. (2008). Human blood neutrophil responses to prolonged exercise with and without a thermal clamp. Journal of applied physiology (Bethesda, Md.: 1985), $104,20-26$.

15. Lancaster, G.I. \& Febbraio, M.A. (2005). Exosome-dependent trafficking of HSP70: a novel secretory pathway for cellular stress proteins. The journal of biological chemistry, 280, 23349-23355.

16. Lee, J.Y., Stone, E.A., Wakabayashi, H. \& Tochihara, Y. (2010). Issues in combining the categorical and visual analog scale for the assessment of perceived thermal sensation: methodological and conceptual considerations. Applied ergonomics, 41, 282-290.

17. Leicht, C.A., Kouda, K., Umemoto, Y., Banno, M., Kinoshita, T., Moriki, T., Nakamura, T., Bishop, N.C., Goosey-Tolfrey, V.L. \& Tajima, F. (2015). Hot water immersion induces an acute cytokine response in cervical spinal cord injury. European journal of applied physiology, 115, 2243-2252.

18. Leicht, C.A., Paulson, T.A.W., Goosey-Tolfrey, V.L. \& Bishop, N.C. (2016). Arm and intensity-matched leg exercise induce similar inflammatory responses. Medicine and science in sports and exercise, Epub Feb 2.

19. Myers, J., Lee, M. \& Kiratli, J. (2007). Cardiovascular disease in spinal cord injury: an overview of prevalence, risk, evaluation, and management. American journal of physical medicine \& rehabilitation / Association of academic physiatrists, 86, 142152.

20. Nakamura, M., Yoda, T., Crawshaw, L.I., Yasuhara, S., Saito, Y., Kasuga, M., Nagashima, K. \& Kanosue, K. (2008). Regional differences in temperature sensation and thermal comfort in humans. Journal of applied physiology (Bethesda, Md.: 1985), $105,1897-1906$.

21. Niess, A.M., Fehrenbach, E., Lehmann, R., Opavsky, L., Jesse, M., Northoff, H. \& Dickhuth, H.H. (2003). Impact of elevated ambient temperatures on the acute immune response to intensive endurance exercise. European journal of applied physiology, 89, 344-351.

22. Ogura, Y., Naito, H., Akin, S., Ichinoseki-Sekine, N., Kurosaka, M., Kakigi, R., Sugiura, T., Powers, S.K., Katamoto, S. \& Demirel, H.A. (2008). Elevation of body temperature is an essential factor for exercise-increased extracellular heat shock protein 72 level in rat plasma. American journal of physiology.Regulatory, integrative and comparative physiology, 294, R1600-7. 
23. Paulson, T.A., Goosey-Tolfrey, V.L., Leicht, C.A. \& Bishop, N.C. (2015). Plasma cytokine and exertional responses in relation to exercise intensity and volume of exercising muscle mass during arm-crank ergometry. Applied physiology, nutrition, and metabolism $=$ Physiologie appliquee, nutrition et metabolisme, 40, 782-787.

24. Rhind, S.G., Gannon, G.A., Shek, P.N., Brenner, I.K., Severs, Y., Zamecnik, J., Buguet, A., Natale, V.M., Shephard, R.J. \& Radomski, M.W. (1999). Contribution of exertional hyperthermia to sympathoadrenal-mediated lymphocyte subset redistribution. Journal of applied physiology (Bethesda, Md.: 1985), 87, 1178-1185.

25. Starkie, R.L., Hargreaves, M., Rolland, J. \& Febbraio, M.A. (2005). Heat stress, cytokines, and the immune response to exercise. Brain, behavior, and immunity, 19, 404-412.

26. Steensberg, A., Fischer, C.P., Keller, C., Moller, K. \& Pedersen, B.K. (2003). IL-6 enhances plasma IL-1ra, IL-10, and cortisol in humans. American journal of physiology.Endocrinology and metabolism, 285, E433-7.

27. Tsan, M.F. \& Gao, B. (2004). Cytokine function of heat shock proteins. American journal of physiology.Cell physiology, 286, C739-44.

28. Wallin, R.P., Lundqvist, A., More, S.H., von Bonin, A., Kiessling, R. \& Ljunggren, H.G. (2002). Heat-shock proteins as activators of the innate immune system. Trends in immunology, 23, 130-135.

29. Welc, S.S. \& Clanton, T.L. (2013). The regulation of interleukin-6 implicates skeletal muscle as an integrative stress sensor and endocrine organ. Experimental physiology, 98, 359-371.

30. Welc, S.S., Judge, A.R. \& Clanton, T.L. (2013). Skeletal muscle interleukin-6 regulation in hyperthermia. American journal of physiology.Cell physiology, 305, 406-413.

31. Welc, S.S., Phillips, N.A., Oca-Cossio, J., Wallet, S.M., Chen, D.L. \& Clanton, T.L. (2012). Hyperthermia increases interleukin-6 in mouse skeletal muscle. American journal of physiology.Cell physiology, 303, C455-66.

32. Whitham, M. \& Fortes, M.B. (2008). Heat shock protein 72: release and biological significance during exercise. Frontiers in bioscience: a journal and virtual library, $13,1328-1339$.

33. Whitham, M., Laing, S.J., Jackson, A., Maassen, N. \& Walsh, N.P. (2007). Effect of exercise with and without a thermal clamp on the plasma heat shock protein 72 response. Journal of applied physiology (Bethesda, Md.: 1985), 103, 1251-1256.

34. Yamada, P., Amorim, F., Moseley, P. \& Schneider, S. (2008). Heat shock protein 72 response to exercise in humans. Sports medicine (Auckland, N.Z.), 38, 715-733. 

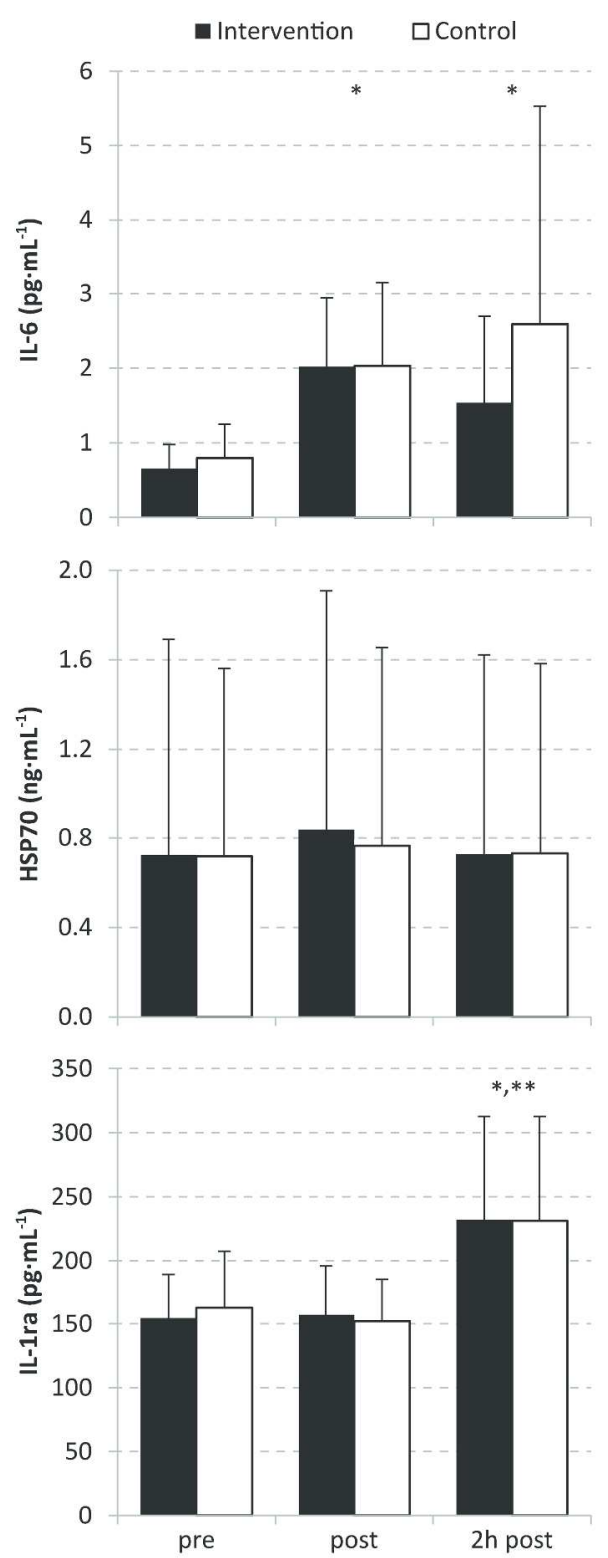

Figure 1 - Interleukin-6 (IL-6), HSP70 and IL-1ra response to arm exercise with (INT) and without (CON) additional clothing. Significantly different from *pre or **post $(P<0.01)$. Figure 1

$202 \times 518 \mathrm{~mm}(300 \times 300$ DPI $)$ 


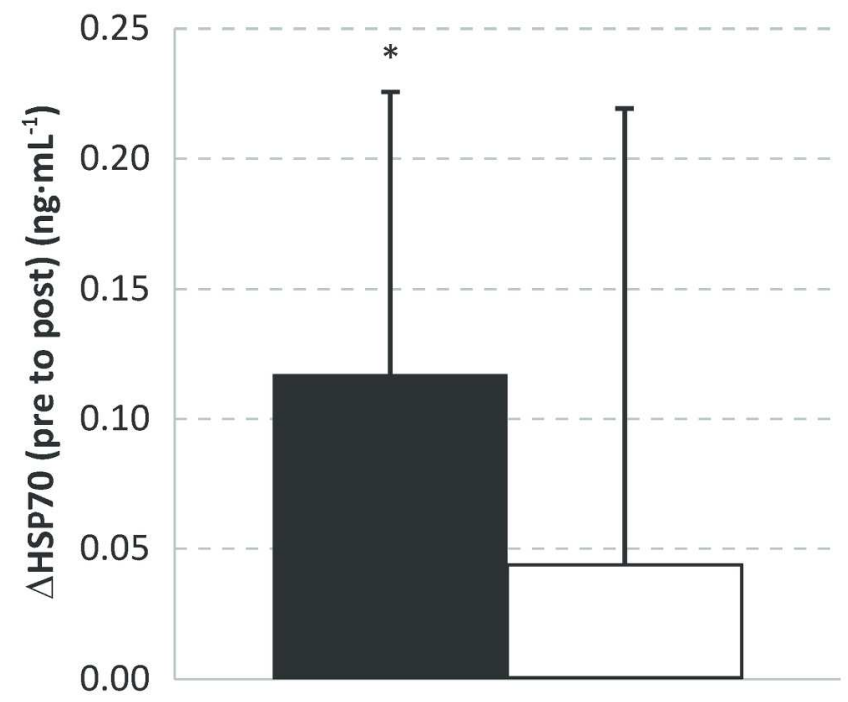

Figure 2 - Increases in IL-6 and HSP70 from pre to post. *Significantly different from Zero $(P<0.05)$. Figure 2 $138 \times 244 \mathrm{~mm}(300 \times 300 \mathrm{DPI})$ 
Figure 3 - Core temperature, core temperature change, mean skin temperature, and heat storage. *Significantly different between conditions $(P<0.05)$.

Figure 3 $156 \times 142 \mathrm{~mm}(300 \times 300 \mathrm{DPI})$ 
Table I - Perceptions of effort, feeling and temperature.

\begin{tabular}{lllllll}
\hline Condition & RPE & RPE & RPE & Exercise & Thermal & Thermal \\
& peripheral & central & overall & comfort & sensation & comfort \\
\hline Intervention & $18^{*}$ & $16^{*}$ & $17^{*}$ & $-4^{*}$ & $19^{*}$ & $1^{*}$ \\
& $(15,19)$ & $(14,17)$ & $(14,18)$ & $(-5,-3)$ & $(17,20)$ & $(0,3)$ \\
Control & 15 & 12 & 14 & -1 & 12 & 8 \\
& $(13,17)$ & $(12,14)$ & $(12,16)$ & $(-3,1)$ & $(10,15)$ & $(5,10)$ \\
\hline RPE, rating of perceived exertion. *Significant difference between conditions, at $\mathrm{P}<0.01$.
\end{tabular}

22

23

26

27

28

29

30

31

32

33

34

35

36

37

38

39

40

41

42

43

44

45

46

47

48

49

50

51

52

53

54

55

56

57

58

59

60

URL: http://mc.manuscriptcentral.com/rjsp 